\title{
APONTAMENTOS PARA EDUCAÇÃO AMBIENTAL PARTICIPATIVA: O PAPEL DA ESCOLA NO ENFRENTAMMENTO DAS QUESTÕES AMBIENTAIS LOCAIS EM UMA COMUNIDADE VULNERÁVEL
}

\section{INDICATIONS PARTICIPATORY ENVIRONMENTAL EDUCATION: THE ROLE OF THE SCHOOL OF ENVIRONMENTAL ISSUES FACING LOCAL COMMUNITY IN A VULNERABLE}

\author{
Edson Chiote Pinheiro', Laísa Freire ${ }^{2}$ \\ ${ }^{1}$ Universidade Federal do Rio de Janeiro-Polo Avançado de Xerém, Instituto de Biologia, Departamento \\ de Biofísica, Mestrado Profissional em Formação Científica para Professores de Biologia, \\ chiote66@oi.com.br \\ ${ }^{2}$ Universidade Federal do Rio de janeiro, Instituto de Biologia, Departamento de Ecologia, Laboratório de \\ Limnologia, laisa@biologia.ufrj.br
}

\section{RESUMO}

$\mathrm{O}$ contexto de investigação do presente estudo refere-se à discussão da Educação Ambiental (EA) a partir de ações entre comunidade e escola em uma comunidade em situação de vulnerabilidade socioambiental. O objetivo geral deste trabalho foi discutir o papel da escola no enfrentamento de problemas ambientais, em uma comunidade em situação de vulnerabilidade socioambiental. Assim, conhecemos a história de ocupação do bairro, identificamos o cenário de vulnerabilidade socioambiental na comunidade e como a EA vem sendo desenvolvida no espaço escolar. Para isso, foram realizadas entrevistas com moradores e questionários com alunos, professores e equipe diretiva da escola, além da análise do Projeto Político Pedagógico e documentos da escola. Os resultados permitiram quantificar indicadores de vulnerabilidade socioambiental da comunidade e identificar no espaço escolar que a EA está sendo trabalhada de forma isolada e restrita a sala de aula. A partir desses dados obtidos foi desenhada uma proposta preliminar de um trabalho de EA. A partir de uma metodologia baseada em premissas participativas, a proposta foi apresentada e discutida com membros do Conselho Escolar, até ser elaborada uma proposta final de um projeto curricular de EA com ações divididas em cinco etapas para um ano letivo. Quando se fortalecem os espaços coletivos de tomada de decisão no espaço escolar, a escola se torna mais permeável ao planejamento de ações de intervenção na realidade ambiental local.

Palavras-chave: Educação Ambiental, Ensino de Ciências, Vulnerabilidade Socioambiental, Interface Comunidade-Escola.

\begin{abstract}
The research context of this study refers to the discussion of environmental education (EE) from actions between community and school in a community in situation of environmental vulnerability. The aim of this study was to discuss the role of schools in to solve environmental problems in a community in situations of environmental vulnerability. So, we know the history of the occupation of the district, identify the scenario of environmental vulnerability in the community and how EE is being developed at school. For this, were performed interviews with residents and questionnaires with students, besides teachers and school management team of the neighborhood, and we analyzed Political Pedagogical Project and school documents. The results allowed us to quantify indicators of environmental vulnerability of the
\end{abstract}


community and identify at school that EE is restricted to the classroom. From these data was drawn a preliminary proposal for EE project. From a participatory methodology based on assumptions, the proposal was presented and discussed with members of the School Council. We drafted final proposal for a study project with EE divided into five steps for a school year. When you strengthen the collective spaces of decision making within the school, the school becomes more permeable for planning actions to intervene in local environmental reality.

Key words: Environmental Education, Science Education, Social and Environmental Vulnerability, school-Community collaboration.

\section{INTRODUÇÃO}

$\mathrm{O}$ contexto de investigação do presente estudo refere-se à discussão da EA a partir de ações entre comunidade e escola. Buscamos refletir sobre as possibilidades de integração entre comunidade e escola a partir da construção de proposta de EA para o enfrentamento das questões ambientais locais. A comunidade situa-se no bairro Parada Morabi, no Terceiro Distrito (Imbariê), do Município de Duque de Caxias-RJ. Suas condições físicas apontam fatores de riscos ambientais, uma vez que a região é repleta de rios e córregos, devido à ocupação das margens de rios e áreas de brejos alagados ou charcos, canalização de leitos, que geram falta de escoamento das águas superficiais e solos impermeáveis.

Em dias de chuvas intensas é comum vários moradores abandonarem suas casas alagadas e procurarem a escola para se abrigar, mas a escola pode ser mais do que um local físico de abrigo, ela pode ser um espaço de construção da cidadania por meio da elaboração de estratégias de superação da situação de vulnerabilidade socioambiental.

Os objetivos iniciais do presente estudo foram: (i) conhecer a história de ocupação da comunidade de Parada Morabi, (ii) caracterizar a situação de vulnerabilidade socioambiental desta comunidade, (iii) identificar como a EA vem sendo desenvolvida no espaço escolar e (iv) construir um processo participativo junto ao conselho escolar de enfrentamento das questões agudas enfrentadas pela comunidade no que se refere aos eventos de alagamentos, enchentes e inundações. Deste modo, a presente investigação apresenta uma implicação social, pois os resultados obtidos nesta investigação foram utilizados para a elaboração de um projeto de EA entre escola e comunidade. 
Sendo assim, na construção deste texto, partimos da problematização das pressões ambientais locais, e refletimos sobre os processos de injustiças sociais, que respondem, pela questão social relacionada às assimetrias sociais gerando um cenário de vulnerabilidade socioambiental da comunidade. Esta discussão teórica é utilizada na significação dos resultados que são apresentados após os procedimentos metodológicos. Tais resultados são discutidos à luz dos pressupostos da gestão ambiental pública e são tecidas considerações sobre as possibilidades e limites da construção participativa de um projeto de EA.

\section{EDUCAÇÃO AMBIENTAL E VULNERABILIDADE SOCIOAMBIENTAL}

O estudo desenvolvido na comunidade tem uma relação com as questões da vulnerabilidade socioambiental, deste modo entendemos que o campo de EA pode ser frutífero para o tratamento das questões ambientais locais.

Há uma relação dos fatores sociais, econômicos, culturais e ambientais na região ao longo da história de ocupação do bairro de Parada Morabi. Todos esses fatores envolvidos e suas relações vêm acarretando uma degradação ambiental na comunidade. Dessa forma, na comunidade, há uma relação entre a dimensão social e ambiental (LOUREIRO, 2003).

Dessa forma, qualquer fenômeno natural pode afetar negativamente as pessoas que vivem na região (DECHAMPS, 2004), nesse caso, a alta intensidade pluviométrica pode levar a população local a uma maior vulnerabilidade, isso ocorre pela ocupação da beira de córregos, canais e rios e a existência de um solo impermeável, que deixa a população em situação de risco a enchentes, inundações e alagamento ${ }^{1}$. A vulnerabilidade social está relacionada com as pessoas que vivem nessas condições e em razão do baixo poder financeiro, não tendo opção de escolha da moradia. Essa região passa a ser a única área acessível, pois apresenta características de risco, desvalorização e ausência de infraestrutura que impossibilita a ocupação de grupo de pessoas com poder econômico maior (TORRES, 1997).

\footnotetext{
${ }^{1}$ Segundo o Ministério das Cidades/IPT(2007), inundação é o transbordamento das águas de um rio, enchente ou cheia é o aumento do nível de água de um córrego ou canal, alagamento é o acúmulo por um tempo de água numa região e enxurrada é grande quantidade de água que corre violentamente, todos relacionados ao alto volume pluviométrico.
} 
Esse risco está associado à incerteza de que vai ou não acontecer, a exposição ao perigo, podendo ter perdas e prejuízos materiais, econômicos e humanos por causa de um desastre natural (CASTRO et al, 2005). Esse último termo é definido por Castro (1998) como resultado de eventos naturais contrários a situação normal, sobre o ambiente vulnerável. Tais eventos, quando tem uma ação de destruição, passam a ser conceituados como ameaças. Estas passam a ser classificadas como mais ou menos graves a partir das condições de vulnerabilidade socioambiental (NARVÁEZ et al., 2009), sendo que a comunidade pode ser atingida de uma forma acentuada, no entanto, grave quando os efeitos dos desastres, cabendo aqui à participação da EA na preparação dos atores sociais, reduzirem os riscos e adquirirem resiliência para esses eventos. Assim, a finalidade da EA é atuar no reconhecimento das desigualdades sociais existentes, a fim de instituir uma ação completa, contextualizada e crítica da realidade, mostrando os problemas estruturais existentes e as causas do baixo padrão de qualidade de vida (LOUREIRO, 2003).

No seu papel ambiental, Guimarães (2007), aborda que o estudante deve ter uma formação cidadã comprometido com o exercício que o faz preparado para o enfrentamento dos problemas socioambientais da região. As propostas educativas elaboradas pela escola devem ser contextualizadas para, além dos seus muros, fazendo uma interação com a comunidade local. A formação social e ambiental que a escola deve fornecer para os seus alunos está baseada na concepção e prática de uma abordagem crítica em relação às formas tradicionais que apresentam características biologizantes, disciplinatórias, moralistas e imediatistas (TOZONI-REIS, 2012). Tal abordagem tem um discurso contrário a atual sociedade e sua relação com a natureza. Ela compõe as correntes de EA transformadora e emancipatória.

Por isso, neste estudo partimos do fato de que a EA escolar pode ter uma importância na formação de estudantes que são componentes da comunidade e que podem e devem participar da gestão ambiental local, enfrentando problemas ambientais da região como as enchentes, alagamentos e inundações, e que estão relacionados ao alto volume pluviométrico. 


\section{COLABORAÇÃO COMUNIDADE - ESCOLA}

A proposta de gestão democrática com a participação da comunidade escolar na elaboração das atividades dentro e fora do ambiente escolar já é sugerida na Constituição Federal de 1998, na Lei de Diretrizes e Bases da Educação-LDB (1996), Parâmetros Curriculares Nacionais-PCNs (1998) e Plano Nacional de Educação-PNE (2014).

Portanto, para que o projeto de EA venha ser viável, acreditamos num contexto de participação da comunidade escolar na elaboração de ações escolares, o que tornará mais eficaz a sua implementação. Nessa perspectiva, a comunidade escolar passa a ser representada pelo Conselho Escolar, órgão que apresenta membros de todos os segmentos da comunidade escolar; sendo assim, eles devem participar das discussões que envolvem as estratégias e ações das atividades planejadas, passando a ser o processo mais democrático criado dentro do ambiente escolar (RODRIGUES e MOLINA, 2012). Isto favorece a integração entre a escola e a comunidade atendida (BEZERRA, et al., 2010).

O Conselho Escolar aparece como um órgão que vai incentivar o envolvimento dos participantes na troca de ideias para tomada de decisões e na elaboração de objetivos e metas. Isso vai demandar dos participantes, durante as discussões, uma seriedade quanto à organização, participação e decisão nas ações em função das necessidades histórico-sociais dos alunos como integrantes da comunidade (RODRIGUES e MOLINA, 2012). O estabelecimento de objetivos reais e fáceis de serem cumpridos no decorrer do tempo estabelecido passa a ser eficiente, já que todos os envolvidos no seu planejamento foram os que definiram e se tornaram os responsáveis pelo seu cumprimento (WESTRUPP, 2003).

A criação - dentro da escola - de um espaço de diálogo entre os pesquisadores que fazem uma abordagem técnica para a conservação do ambiente, com os moradores da localidade que trazem uma abordagem local, através de um contexto histórico, cultural, social e subjetivo da vulnerabilidade socioambiental, faz aumentar a compreensão da vulnerabilidade da região, a partir de uma visão sobre a realidade da localidade (SOUZA e CERATI, 2013). Essa troca de saberes passa a ser importante para planejar as ações que serão viáveis para reverter a situação da vulnerabilidade socioambiental da comunidade e não ficando apenas no papel. 


\section{PROCEDIMENTOS METODOLÓGICOS}

O estudo foi iniciado no ano de 2012 e inicialmente foi feito um questionário de pesquisa aos alunos composto por 28 perguntas fechadas, sendo 21 dicotômicas (questões onde se pode escolher apenas um item dentre as opções) e sete de múltipla escola (questões onde se podem assinalar vários itens), sendo dividido em dados: da família, do domicílio, sobre comunicação, sobre o bairro e sobre ação dos fenômenos naturais. A aplicação foi para 300 alunos voluntários do $3^{\circ}$ ao $9^{\circ}$ ano do Ensino Fundamental e da Educação de Jovens e Adultos (EJA) da escola do bairro. Todos conheceram o motivo da pesquisa e foram autorizados pelos responsáveis através do Termo de Consentimento Livre e Esclarecido (TCLE), conforme a Resolução 196/96 do Conselho Nacional de Saúde. De acordo com Bogdan e Biklen (1982), a autorização através da negociação é uma etapa importante para que ocorra a pesquisa. Segundo esses autores, durante a negociação, o investigador deve ter clareza com os termos do acordo, devendo respeitar o pesquisado durante o estudo. Os autores sugerem ainda que as identidades dos sujeitos não devem ser expostas, para que a informação que o investigador recolhe não venha causar qualquer tipo de constrangimento.

Assim sendo, os questionários dos alunos foram todos respondidos sem identificação. Antes da aplicação, fizemos um piloto com 50 alunos de vários níveis de escolaridade, com intuito de adequar as questões ao nível dos respondentes. Posteriormente, ocorreu o preenchimento definitivo. As questões foram lidas pelo pesquisador e dadas um tempo suficiente para a marcação da resposta.

O questionário de pesquisa para docentes seguiu o modelo elaborado pelo INEP $^{2}$ (2006), composto por 23 perguntas, sendo 13 dicotômicas, sete de múltipla escolha e duas para ordenar prioridades (as três primeiras, dentre algumas opções). A primeira parte do questionário dedica-se à identificação profissional do respondente, ressaltando-se aspectos como cargo e formação. A partir da $5^{\mathrm{a}}$ questão, o questionário volta-se para a investigação de como foi implementada a EA nas escolas. Na terceira parte, foca-se o papel dos diferentes atores na implementação, desenvolvimento e gestão de EA na escola. O questionário termina com uma pergunta referente às principais dificuldades encontradas no desenvolvimento da EA. Em seguida, há quatro questões abertas com objetivo de complementar às informações já obtidas. A aplicação foi para

\footnotetext{
${ }^{2}$ Instituto Nacional de Estudo e Pesquisas Educacionais Anísio Teixeira 
20 professores voluntários do Ensino Fundamental, que após as instruções do preenchimento e a finalidade da pesquisa, receberam os questionários.

As entrevistas com os moradores foram do tipo semi estruturada. Através de um roteiro de perguntas elas foram gravadas com duração de tempos diferentes para cada participante: 50 minutos para participante Arlinda $^{3}, 40$ minutos para os participantes Américo, Aracy, Castro ${ }^{4}$ e 55 minutos com a participante Elvira ${ }^{5}$. Nesta contagem excluímos os momentos iniciais e finais da conversa informal, sendo a conversa formal, do roteiro de perguntas, integralmente transcritas. As cinco entrevistas foram especificamente para coletas de dados da ocupação do bairro, ação do poder público ao longo do tempo, evolução da vulnerabilidade socioambiental e histórico da escola na comunidade.

A coleta dos dados em documentos ocorreu no ano de 2013 na secretaria da escola. Com o auxílio da equipe diretiva, foram investigados o seu Projeto Político Pedagógico (PPP) de 2011 e 2012, os registros com os dados da sua inauguração e transferência para outros locais, além do histórico do seu patrono. À medida que surgia dados de interesse, eles eram transcritos ou fotocopiados. Organizamos no ano de 2013 todas as cópias e transcritos e através de uma leitura identificamos com um marcador de texto as frases ou parágrafos que iam constituir no final um resumo do histórico da escola e do seu patrono, além dos projetos de EA previstos no PPP.

Após a coleta e análise dos dados, utilizamos os resultados obtidos nesta primeira etapa da investigação, no início do ano de 2014, para elaboração de um projeto de EA com a participação do Conselho Escolar. Validamos os resultados das coletas de dados com os seus integrantes, discutimos a elaboração de um projeto de EA específico, orientado pelo pesquisador, cujo objetivo foi propor encaminhamentos para a situação de vulnerabilidade socioambiental. Assim sendo, foram realizados dois grupos de discussão para elaboração do projeto. Participaram da construção: três moradores, dois estudantes da Educação de Jovens e Adultos (EJA), um estudante do Ensino Fundamental (EF), dois funcionários de apoio, um orientador pedagógico (OP), três professores e um pesquisador.

Após solicitação, foi marcada uma primeira reunião com o pesquisador, pelo presidente do Conselho Escolar, nas dependências da escola, na qual foram mostrados

\footnotetext{
${ }^{3}$ Nome fictício.

${ }_{5}^{4}$ Nomes fictícios.

${ }^{5}$ Nome fictício.
} 
para os membros os resultados tabulados e o histórico socioambiental da comunidade de Parada Morabi. Nesta reunião, houve a validação dos resultados, debate e explosão de ideias sobre propostas de projetos de EA. Esse encontro teve duração de 80 minutos e foi registrado em áudio com consentimento dos participantes. Nesta contagem excluímos os momentos iniciais e finais da conversa informal. A partir deste encontro, desenhamos uma proposta preliminar que foi apresentada para o conselho. Em nova reunião foi discutido como trabalhar a EA na escola envolvendo toda comunidade, com objetivo delinear o projeto. O segundo grupo de discussão durou 40 minutos, onde também excluímos da contagem os momentos iniciais e finais da conversa informal, e teve sua discussão gravada em áudio. Após a construção junto ao conselho o projeto foi sendo trabalhado pelos pesquisadores envolvidos de modo a "lapidar" coerência teórica, pois percebemos a polissemia da EA materializada nas propostas de intervenção. Os dados obtidos na reunião foram utilizados na elaboração do projeto.

\section{RESULTADOS E DISCUSSÃO - RECONSTRUÇÃO DO HISTÓRICO DA COMUNIDADE DE PARADA MORABI}

O bairro Parada Morabi, localizado no $3^{\circ}$ distrito Imbariê, teve um histórico semelhante ao seu Município. Morabi apresentava um ecossistema revestido pela Floresta Ombrófila Densa das Terras Baixas (MONTEZUMA et al., 2009). No século XIX, com a instalação da Fazenda Anhangá ${ }^{6}$ perto dos seus rios, esta formação foi destruída para a prática agrícola, utilizando a mão de obra escrava. Assim, sofrendo o seu primeiro impacto ambiental. Com o encerramento da agricultura, devido o eixo econômico do Brasil mudar para o ouro, essa área passou a ter um ecossistema de Campo/Pastagem, com algumas áreas inundáveis e predomínio de brejos. Como comentado pela D. ${ }^{a}$ Araci “[...] quando cheguei aqui, Morabi era tipo brejo [...]”. Observamos que os primeiros moradores no início do século XX eram descendentes de escravos. O Sr. Castro relata esse fato "[...] quando aqui cheguei conheci os descendentes dos escravos da "FAZENDA", já livres, claro, porém permaneceram em seus antigos lares”. Em 1963 já não mais existiam, porém a fazenda permanecia em

\footnotetext{
${ }^{6}$ Anhangá, segundo Pereira (2004), é o nome que os índios tupis da América do Sul davam aos espíritos que vagavam pela terra após a morte, atormentando os viventes. Segundo alguns mitos também o protetor da caça nas florestas. Os jesuítas utilizavam o vocabulário para se referir ao demônio cristão.
} 
perfeito estado de conservação, a senzala, o fosso, o tronco,... estavam todos lá ainda, inclusive com algumas famílias residindo na Casa dos Empregados [...]”.

Os primeiros moradores chegaram a partir de 1950, e tinham o trem como único meio de transporte, e encontraram uma região bem diferente da atual, como $S r$. Américo relata “[...] quando cheguei a Morabi em 1962, não tinha luz e tudo era brejo [...]”. D. ${ }^{a}$ Arlinda acrescenta “[...] em 1963 a rua principal, Avenida Anhangá, era apenas uma trilha e dos lados brejos. Onde é a estação atual havia seis casas de estuque cobertas de sapê, elas eram montadas com varas e cobertas de barro por dentro e por fora, o chão era de barro pisado. O único meio de transporte era o trem, que ainda era a antiga "Maria Fumaça", logo surgiu máquina a óleo que puxava vagões de madeira [...]”. O crescimento populacional da região foi através de fluxos migratórios para mão de obra na construção civil, impulsionado pela acessibilidade à região com inauguração da rodovia Rio-Magé (BR 493), durante o plano de Metas Governo de Juscelino Kubitschek (1956-1961), que estimulava o processo de industrialização perto da região (ABREU, 2006, p. 107). Houve nessa época um estimulo ao loteamento com intenso fluxo migratório para Parada Morabi. Como D. ${ }^{\text {a }}$ Elvira comenta “[...] a prefeitura sedia o terreno de graça para morar aqui. Na época do governador Brizola ele veio aqui em Morabi, todo mundo que tinha casa em barraquinho ele deu um pedaço de terra. E daí tinha um papel que ele deu [...]”. Os primeiros moradores tomaram posse dos terrenos, numa área plana e brejosa, com pouca inclinação, que retardava ou impedia o deslocamento de água. Assim sendo, o relato de inundações já ocorria há muito tempo, como D. ${ }^{2}$ Elvira relata "[...] minha casa já ficou 5 dias com água até aqui na cintura, tive que pegar um moço para emboçar a parede depois disso. Isso aconteceu há muito tempo atrás [...]”.

Segundo Montezuna et al. (2009), a destruição das florestas, sua urbanização e consequência impermeabilização do solo, representam um fato relevante ao agravamento das enchentes e dos alagamentos.

\section{CONDIÇÕES SOCIOAMBIENTAIS DA COMUNIDADE}

A tabela a seguir (tabela 1) mostra o resultado do levantamento da situação de vulnerabilidade no aspecto de infraestrutura a partir de indicadores socioambientais (JANKE e TOZONI-REIS, 2008). Analisando os indicadores, as residências são pequenas com poucos cômodos chegando a $46 \%$ com cinco ou mais pessoas por casa, com muitas crianças e mulheres. A forma de abastecimento de água dessas pessoas é 
$82 \%$ através do poço, maioria de anel, não profundo, perto da fossa ou vala, o que aumenta o risco de contaminação. A saída de esgoto do banheiro das residências é $45,34 \%$ direcionada para fossa, $28 \%$ para vala, $22 \%$ para a rede pluvial e $4,33 \%$ para o rio e 0,33\% latrina. Observamos que o saneamento básico não existe. A energia elétrica que impulsionou a região ainda não existe para $3 \%$ dos alunos, sendo utilizado lampião. A construção de uma praça e uma quadra de futebol em 2011 passou a ser o único lazer para a comunidade.

Em relação aos dados sobre vulnerabilidade, verificamos que $60 \%$ dos alunos já tiveram suas ruas atingidas por alagamento, seguidos por $28 \%$ inundações e $8 \%$ enchentes. Isto é observado pelo número de alunos que moram perto de rios e canais. Destes, $138(46 \%)$ tiveram suas casas atingidas, sendo $70(50,73 \%)$ com perdas materiais.

Desabrigados ou desalojados foram 54 (39\%), os desabrigados ficam na escola que passa a ser ocupada pela defesa civil, sendo interrompidas as aulas e alterando o calendário escolar.

Dos 300 alunos, 76\% se consideram um morador que possa sofrer uma das ameaças naturais que atingem a região e isso é devido à metade morarem perto de rios, lagos ou canais. No caso da resiliência $68 \%$ não sabem o que fazer e $81 \%$ acham que a degradação do meio ambiente aumenta o risco de ameaça natural, porém $19 \%$ acham que não. Isso mostra a necessidade de um trabalho de EA com maior expressividade, com uma abordagem mais específica da situação de vulnerabilidade socioambiental da comunidade. 
Tabela 1: Resultados da caracterização socioambiental do bairro Parada Morabi a partir de questionários com estudantes da localidade

\section{INDICADORES SOCIOAMBIENTAIS}

BAIRRO PARADA MORABI- 2012

Porcentagem/número absoluto

\section{RESIDÊNCIAS:}

Quantidades de moradores:

- Até três: $18 \%$ / 18 Até quatro: $36 \% / 107$ Cinco ou mais: 46\% / 139

Abastecimento de água:

- Poço: 82\%/246 Através de cano: 4,66\%/14

Nascente: $2 \%$ / 6 Outra: $11,34 \% / 34$

Forma de saída de esgoto:

- Fossas: 45,34\% / $136 \quad$ Vala: 28\% / $84 \quad$ Rede: $22 \%$ / 66

Rio ou Lago: 4,33\% / 13 Outros/Latrina: 0,33\% / 1

\section{VULNERABILIDADE DOS MORADORES:}

Moram perto de rios e canais:

- $\quad$ Sim: $52 \%$ / $157 \quad$ Não: $48 \% / 143$

Ruas atingidas por ameaças naturais (enchentes, inundações e alagamentos):

- Alagamentos: 60\%/180 Inundações: 28\% / 84 Enchentes: 8\% / 24

Casas atingidas por ameaças naturais (enchentes, inundações e alagamentos):

- Sim: $46 \% / 138$ Não: $54 \% / 162$

Consideram ameaçados por enchentes, inundações e alagamentos:

- Sim: $76 \% / 228$ Não: $24 \% / 72$

Ficaram desabrigados:

- Sim: $39 \%$ / 54 Não: $61 \%$ / 84

\section{RESILIÊNCIA:}

Sabem o que fazer para evitar as ameaças:

- Sim: $32 \% / 97$ Não: $68 \% / 203$

\section{EDUCAÇÃO AMBIENTAL:}

Acham que a degradação ambiental aumenta o risco de desastres naturais

- Sim: $81 \% / 243 \quad$ Não: $19 \% / 57$

Os dados quantitativos se relacionam positivamente com os qualitativos quando na realização das entrevistas com os moradores. Em alguns trechos das falas dos entrevistados foi possível também caracterizar a situação de vulnerabilidade. $\mathrm{Na}$ entrevista $D^{\text {a }}$ Arlinda, uma moradora do bairro, mostra que a vulnerabilidade socioambiental a desastres ambientais na comunidade não é recente. Vejamos no 
seguinte fragmento: “[...] desde que cheguei aqui às ruas sofrem enchentes. Uma delas ocorreu em 1986 e atingiu muitas pessoas, que perderam os seus móveis e só conseguiram passar pelas ruas de barco. Foi na Escola municipal que a população se abrigou, até que as águas permitissem o retorno aos seus lares [...]”. Ainda na fala de entrevistados é possível perceber o crescimento desordenado. O crescimento da região ocorreu sem saneamento básico desde 1950 com a chegada dos moradores, como relata na entrevista Sr. Américo um dos primeiros moradores: "[...] o bairro aos poucos progredia, porém muito lentamente. O crescimento veio acompanhado de lixo, esgoto, falta de água e atendimento médico [...]”. A primeira ação pública na região foi a construção da Escola Municipal em 1981, havendo ampliação e calçamento da principal avenida do bairro (Avenida Anhangá), permitindo a circulação de mais veículos, inclusive ônibus. Isto demonstra a ausência do poder público durante vários anos. Algumas ruas paralelas a principal foram asfaltadas e receberam manilhamento, porém os alunos apontaram a falta de asfalto como o principal problema do bairro.

\section{DIFERENTES ABORDAGENS DE EA NA ESCOLA}

Os PPPs de 2011 e 2012 não preveem nenhum trabalho de EA na escola.

Dos 30 questionários entregues aos professores, 20 foram respondidos de forma parcial, se baseando em trabalhos isolados de alguns professores durantes os últimos anos e 10 não respondidos totalmente. As respostas foram de docentes de todas as áreas curriculares e de ambos os segmentos do Ensino Fundamental, onde 19 (95\%) possuem Ensino Superior completo, desses 18 com especialização, um com mestrado, e outro (5\%) com Ensino Superior incompleto.

Quando perguntados se a escola desenvolve EA, houve percepções diferenciadas entre os docentes. Enquanto $40 \%$ responderam que a escola não desenvolve EA, 60\% dizem que sim (tabela 2). Isso surgiu no relato de alguns professores como a professora Fátima "[... a a EA é pouco explorada sendo fadada (sic.) apenas em ocasiões especiais, não considero desenvolvida na escola [...]” e Fernando “[... ] a EA é precária parte da iniciativa isolada de um ou outro professor [...]”. Na visão deles, a escola não deixou de trabalhar a EA, porém é enfatizada de forma isolada, em alguns períodos e sem expressividade, o que permite a sua obscuridade no contexto escolar, fazendo com que os muitos docentes não percebam sua existência. 
Tabela 2: Porcentagem de docentes com o tempo que desenvolvem EA na escola

\begin{tabular}{lcc}
\hline \multicolumn{1}{c}{$\begin{array}{c}\text { Tempo que a escola } \\
\text { desenvolve EA: }\end{array}$} & Quantidade & $\%$ \\
\hline Menos de 1 ano & 1 & 5 \\
De 1 a 3 anos & 1 & 5 \\
De 3 a 7 anos & 0 & 0 \\
De 7 a 9 anos & 2 & 10 \\
De 9 a 10 anos & 1 & 5 \\
Mais de 10 anos & 7 & 35 \\
Não desenvolve & 8 & 40 \\
TOTAL & 20 & 100 \\
\hline
\end{tabular}

Segundo Tozoni-Reis (2012), a introdução da EA na escola pública é desafiadora, devido a toda complexidade existente neste espaço público. Mesmos assim, segundo os respondentes, a escola começou a trabalhar com EA provocada pela iniciativa de um professor ou grupo de professores, seguido pelos que dizem que foi por um problema ambiental na comunidade relacionado à falta de saneamento básico (tabela 3). Portanto, embora possamos apontar certa eficiência no caráter estimulador das políticas públicas, os dados anteriores demonstram que, de maneira geral, as escolas têm iniciado os trabalhos, muito mais estimuladas por iniciativas individuais do que por ações institucionalizadas, oriundas de instâncias públicas, programas ou projetos governamentais, com capacidade inicial de fomentar a ação coletivizada.

Tabela 3: Porcentagem de docentes indicando com a EA começou a ser trabalhada na escola

\begin{tabular}{lcc}
\multicolumn{1}{c}{$\begin{array}{c}\text { A Escola começou a trabalhar } \\
\text { com EA provocada por: }\end{array}$} & Qde & \% \\
\hline Iniciativa de um professor ou um grupo de professores & 9 & 45 \\
\hline Problema ambiental na escola & 8 & 40 \\
\hline Parâmetros em ação: meio ambiente na escola & 4 & 20 \\
\hline Diretriz da Secretaria Municipal de Educação & 2 & 10 \\
Conferência Nacional Infanto-Juvenil para o meio ambiente & 0 & 0 \\
\hline Interesse dos alunos & 0 & 0 \\
Notícias vinculadas na mídia (TV e jornal) & 0 & 0 \\
Políticas e programas Nacional e Estadual de EA & 0 & 0 \\
Projeto de empresa & 0 & 0 \\
Projeto de ONG & 0 & 0 \\
Outros & 0 & 0 \\
\hline
\end{tabular}

Em ordem de importância os três principais objetivos da EA na escola, na visão dos professores entrevistados, são: primeiro, intervir na conscientização dos alunos e comunidade para plena cidadania, segundo, intervir na comunidade e terceiro, promover o desenvolvimento sustentável. Isto demonstra que os professores têm uma dimensão do papel de EA que merece ser mais trabalhada de modo a adotar referenciais críticos e sua relação com a possibilidade do enfrentamento dos problemas ambientais locais. 
Tabela 4: Porcentagem de docentes indicando os três principais objetivos da EA na escola

Os três principais objetivos da EA na escola,

Qde \% em ordem de importância:

PRIMEIRO: Conscientizar alunos e comunidade para plena cidadania

Segundo os dados divulgados pelo relatório final da pesquisa realizada pelo MEC em 2006, O que fazem as 118 escolas que dizem que fazem EA na região Sudeste, $79 \%$ das escolas afirmam que o meio mais utilizado para trabalhar a EA foi através de projetos. As demais modalidades aparecem com: 55\% a inserção através das disciplinas específicas e 52\% através do Projeto Político Pedagógico (PPP) (LIMA e VASCONCELLOS, 2007). Essa tendência não foi observada na escola, onde $50 \%$ dos docentes afirmam que a EA é desenvolvida na escola por meio de inserção da temática em disciplinas específicas, seguidos por $20 \%$ cada, projetos e através de PPP e 5\% cada, datas e eventos significativos e atividades comunitárias (tabela 5). A utilização de projetos constitui-se, de acordo com os Parâmetros Curriculares Nacionais numa alternativa pedagógica promitente, ao contrapor-se à organização educacional tradicional, que está baseada nos conteúdos específicos, assegurados nos programas de cada disciplina do currículo escolar (BRASIL, 1998). Como a comunidade apresenta vários problemas socioambientais os projetos deveriam ser realizados a partir dessa problematização e também sob o enfoque dirigido à solução desses problemas.

Tabela 5: Porcentagem de docentes indicando com a EA é desenvolvida na escola

\begin{tabular}{lcc}
\hline \multicolumn{1}{c}{$\begin{array}{c}\text { A EA é desenvolvida na } \\
\text { escola por meio de: }\end{array}$} & Quantidade & \% \\
\hline Inserção da temática em Disciplinas Específicas & 10 & 50 \\
Projetos & 4 & 20 \\
Inserção no PPP( Projeto Político Pedagógico) & 4 & 20 \\
Datas e Eventos significativos & 1 & 5 \\
Atividades Comunitárias & 1 & 5 \\
Disciplina Especial & 0 & 0 \\
TOTAL & 20 & 100 \\
\hline
\end{tabular}


Atores de maior destaque que são envolvidos nos projetos de EA na escola são grupos de professores e alunos (tabela 6). O estudo revelou a necessidade de maior participação de outros membros da comunidade nos projetos de EA que a escola pode desenvolver, devido a sua vulnerabilidade socioambiental.

Tabela 6: Porcentagem de docentes indicando quais os atores envolvidos nos projetos de EA

\begin{tabular}{|c|c|c|c|}
\hline $\begin{array}{l}\text { Os projetos de EA envolvem os seguintes } \\
\text { atores: }\end{array}$ & Sim & Não & Eventualmente \\
\hline Apenas um professor & $4=40 \%$ & $4=40 \%$ & $2=20 \%$ \\
\hline Grupo de professores & $6=60 \%$ & $1=10 \%$ & $3=30 \%$ \\
\hline Equipe da direção & $4=40 \%$ & $2=20 \%$ & $4=40 \%$ \\
\hline Funcionários & $2=20 \%$ & $7=70 \%$ & $1=10 \%$ \\
\hline Alunos & $8=80 \%$ & $1=10 \%$ & $1=10 \%$ \\
\hline ONG & $0=0 \%$ & $10=100 \%$ & $0=0 \%$ \\
\hline Comunidade & $4=40 \%$ & $3=30 \%$ & $3=30 \%$ \\
\hline Empresas & $0=0 \%$ & $9=90 \%$ & $1=10 \%$ \\
\hline Universidade & $0=0 \%$ & $9=90 \%$ & $1=10 \%$ \\
\hline Outros & $0=0 \%$ & $0=0 \%$ & $0=0 \%$ \\
\hline
\end{tabular}

É desejável que esse envolvimento alcance níveis semelhantes aos dos atores internos (professores, alunos e equipe diretiva). Acreditamos que uma EA, capaz de contribuir no enfrentamento da crise socioambiental que vivenciamos, é aquela que faz do ambiente educativo espaços de participação da comunidade, em que a aprendizagem se dá em um processo de construção de conhecimentos do cotidiano, que execute ações que tenham a intencionalidade, como uma ação política, de intervir na realidade transformando-a. Trazer a realidade de fora da escola para dentro e retornando com ações educativas na comunidade é o pressuposto de uma abordagem relacional. Todo 
esse processo é um ambiente educativo propício para o desenvolvimento de uma EA em seu caráter crítico, que se inicia na escola, mas se realiza para além de seus muros.

A interação entre comunidade-escola através da EA possibilita uma melhoria no entorno da unidade escolar, maior sensibilização dos moradores para a conservação dos patrimônios existentes, a redução do volume dos resíduos sólidos no bairro, maior participação da comunidade no diálogo com o poder público para melhoria das condições socioambientais e a formação de associações e órgãos não governamentais ambientalistas.

A formação dos professores em EA ocorre por conta própria, porém, a Secretaria Municipal de Educação, através de capacitação, também contribui para esse aperfeiçoamento. Apesar desses dois eventos a maioria dos professores da escola não é capacitada para trabalhar com EA. Como mostra o relato do professor Augusto " [...] É necessário saber: O que significa EA? Onde buscar os seus conteúdos? Como implementar? Como abordar?[...]”. O indício neste caso pode estar impedindo um trabalho mais expressivo e direcionado deste tema na unidade escolar. A precariedade de recursos materiais, falta de tempo para planejamento, realização de atividades extracurriculares e da dificuldade da comunidade escolar de entender as questões ambientais são dificuldades apontadas pelos docentes para o não desenvolvimento da EA na escola. As perspectivas da EA na escola para os próximos três anos são de uma maior intervenção em relação ao quadro atual, como comentado pelos professores: Cesar " [...] acredito que seja reforçada no PPP e ser promotora de projetos interdisciplinar [...]”, Fátima “[...] com uma integração crítica e inovadora, mas de participação ativa da comunidade local [...]”, Joana “[...] de forma coletiva entre todos da escola [...]” e Antônio [...] que atinja os problemas da comunidade que são refletidas diretamente no ambiente escolar. Como as constantes enchentes que impedem a frequência escolar e muitos necessitam abrigar-se no prédio escolar [...]”.

\section{O DESENHO DE UMA PROPOSTA DE TRABALHO DE EA}

No primeiro grupo de discussão o pesquisador iniciou destacando a importância do Conselho Escolar no processo de tomada de decisão e organização da escola. Continuou fazendo considerações precisas sobre o desenho do projeto de EAl para um ano letivo. Observamos que a participação dos membros do Conselho Escolar não era igualitária. A equipe diretiva e professores foram os que falaram mais e contribuíram com várias ideias, sempre aceitas pelo grupo. A participação dos 
moradores, funcionários, pais e alunos, apesar de pequena, teve grande importância na validação dos dados e no direcionamento das ações propostas nas discussões. No segundo grupo de discussão a participação dos membros foi igualitária. Observamos uma interação maior dos participantes e um maior número de ideias provenientes dos moradores.

Nessas discussões, optou-se pelo desenvolvimento de um projeto que durasse todo ano letivo. O objetivo geral do projeto elaborado foi o de tornar toda comunidade escolar capacitada através de processos educativos orientados, fazendo uma relação com os conteúdos do Ensino de Ciências, ao enfrentamento dos problemas ambientais locais, inclusive preparando os envolvidos para se mobilizarem de maneira preventiva em situações de emergência, minimizando e evitando desastres ambientais.

Como estratégia e ações dividimos o projeto para um ano letivo em cinco etapas: A $1^{\mathrm{a}}$ etapa propomos a organização, pelo Conselho Escolar, da EA na escola com interessados em realizar ações voltadas à melhoria do meio ambiente e qualidade de vida, promovendo o intercâmbio entre a escola e a comunidade num sábado letivo, e contribuir assim para um dia a dia participativo, democrático, inclusivo, animado e saudável. Como integrantes teremos estudantes, professores, funcionários, pais e membros da comunidade. Para formação deste grupo sugerimos que o Conselho Escolar reúna quem se interessa pelo tema Sustentabilidade e Meio Ambiente na Escola ou na Comunidade. Seguindo as propostas da carta Elos de Cidadania $^{7}$, este grupo deve trabalhar: (1) para a mobilização da comunidade escolar na efetiva e responsável gestão democrática da escola; (2) para fortalecimento do Conselho Escolar, divulgando a sua importância perante a Comunidade Escolar; (3) para debater de forma permanente, entre os membros da comunidade escolar, os aspectos formativos da inserção da escola nos espaços públicos de participação na gestão ambiental pública, orientando as comunidades do entorno da escola para revitalização de espaços, fontes, rios e matas.

Assim sendo, para a $2^{\mathrm{a}}$ etapa, o grupo formado deve promover para os moradores dessas áreas e os estudantes, durantes os dias letivos, palestras, peças teatrais, exposição de fotos e trabalhos de medidas de prevenção contra as ameaças naturais, com os temas: Resiliência: Como agir em caso de enchentes, inundações ou

\footnotetext{
${ }^{7}$ Carta Elos de Cidadania: A escola Pública na Gestão Ambiental: Manifesto coletivo de educadores e educadoras pelo fortalecimento da instituição escolar enquanto sujeito ativo na gestão ambiental pública. O texto-base da Carta foi formulado no âmbito do Programa Elos de Cidadania e foi debatido no Fórum Elos de Cidadania, realizado na UERJ, no dia 13 de setembro de 2013, com a participação de 200 pessoas.
} 
alagamentos? / Prevenção: As mudanças climáticas e suas relações com as ameaças naturais. /Quais as maneiras de se prevenir contra doenças, antes, durante e após essas ameaças? / Mitigação: Como reduzir a vulnerabilidade socioambiental às ameaças naturais?

Para a $3^{\text {a }}$ etapa o grupo deve construir o mapa da comunidade com as áreas de riscos a inundações, enchentes e alagamentos. Os seus membros devem identificar, através de visita ao local nos finais de semana e pesquisa com os alunos durante os dias letivos, as ruas que sofrem essas ameaças. O mapa elaborado deve ser utilizado durante as aulas de Ciências para ser debatido as questões socioambientais locais, tornando a sala de aula um espaço de diálogo para o mapeamento de problemas e conflitos socioambientais da região e posterior planejamento de ações de intervenção na realidade ambiental local, sendo uma delas a criação de um sistema de alerta.

Assim, a criação de um sistema de alerta fará parte da $4^{\mathrm{a}}$ etapa. O grupo tendo como base o mapa de áreas de riscos criará uma rede de contato, entre alunos e membros da comunidade, através da internet e telefone, desenvolvendo, capacitações para gestão de emergências, realizando, com regularidade, nos sábados letivos, simulados para preparação do público geral, nos quais participam todos os habitantes locais. O sistema de alerta serve para que os moradores possam sair com segurança das suas residências para se alojar na escola e deve ser monitorado por um grupo de alunos e membros da comunidade que em dias de chuvas fortes acompanham pela internet o nível de água do rio Saracuruna, através do sistema de Alerta de Cheias do Instituto Estadual do Ambiente (< http://inea.infoper.net/inea >). Os moradores também podem monitorar os seus pluviômetros existentes nas suas residências. Eles serão construídos na escola pelos alunos, orientados pelos professores de Ciências. A construção é com garrafa PET de 2 litros e distribuídos paras os moradores das áreas de riscos, sendo mostrada, durante visita ao local, sua finalidade, utilização, importância e onde devem ser colocados.

A $5^{\text {a }}$ etapa é o monitoramento e avaliação das ações. O monitoramento é importante para acompanhar o andamento das ações, para corrigir rumos e adequar materiais e prazos em função do alcance dos objetivos: O plano de ação está sendo cumprido? / Por quê? . Para o monitoramento, depois de cada atividade, fazer uma rodada com os participantes respondendo a três questões: Que bom que... / Que pena que... / Que tal se... . Temos que verificar se as nossas ações ajudaram a resolver os 
problemas identificados e causaram os impactos que desejamos. Algumas perguntas para que possamos medir e depois comparar os resultados: Qual era a situação antes das ações? / Como está a situação durante as ações? / Qual a situação depois das ações?

Para a avaliação sugerimos: Realizar entrevistas com as pessoas e com os parceiros que se envolveram no projeto. / Aplicar questionários antes e depois do projeto para comparar os resultados ao longo do tempo.

\section{CONSIDERAÇÕES FINAIS}

A análise dos resultados mostra que a vulnerabilidade socioambiental na comunidade a enchentes, inundações e alagamentos é decorrente de um processo de exclusão de determinados grupos sociais que acabam à margem da sociedade, com investimentos precários por parte do poder público, sendo o trabalho de EA na escola realizado de forma isolada, em alguns períodos e restrito à sala de aula. Para superar e dar protagonismo à comunidade, criamos um grupo de discussão com os membros do Conselho Escolar da escola do bairro, no qual a escola passou a interagir com a comunidade do entorno propondo uma ação efetiva de enfrentamento das questões socioambientais mais prementes na comunidade como os eventos de inundações, enchentes e alagamentos.

A estratégia de fortalecer o Conselho escolar afilia-se com pressupostos da gestão ambiental pública no sentido de fortalecer mecanismos da gestão do território. $\mathrm{O}$ conselho tem representantes de todos os segmentos da comunidade e pode ser um ator social ativo atuando como um espaço permanente de diálogo entre escola e comunidade. Deste modo, a escola configura-se com um papel ativo na gestão do território.

\section{REFERÊNCIAS BIBLIOGRÁFICAS}

AYOADE, J. O. Introdução a climatologia para os trópicos. $6^{\text {a }}$ ed. - Rio de Janeiro: Bertrand, Barsil, 2001.

ABREU, Mauricio de A. Evolução urbana do Rio de Janeiro. Rio de Janeiro: IPP, 2006.

BEZERRA, Z.F.; SENA, F.A; DANTAS, O.M.S.; CAVALCANTE, A.R.; NAKAYAMA, L.; SANTANA, A.R. Comunidade e escola: reflexões sobre uma integração necessária. Educar, maio/ago. Editora UFPR- Curitiba, n.37, p.279-291 2010. 
BOGDAN, R.; BIKLEN, S. K. Qualitative Reserch for Education: on introduction for to theory and methods. Boston: Allyn and Bacon, 1982.

BRASIL. Constituição Federal da República Federativa do Brasil de 05/10/1988. 1988.

BRASIL. Ministério do Meio Ambiente. Lei n. 12.187/2009. Dispõe sobre a Política Nacional sobre Mudanças do Clima-PNMC e dá outras providências. Disponível em < www.planalto.gov.br>. Acesso em: 1 jan.2014

CASTRO, A.L.C. Glossário de defesa civil: estudos de riscos e medicina dec desastres:MPO/Departamento de Defesa Civil, 1998. 283p.

CONTI, J.B. \& FURLAN, S. A. Geoecologia: O clima, os solos e a biota. In: Geografia do Brasil/Junrandyr Ross(org)- 5 a ed. Ver.ampl.-São Paulo: editora da USP, 2005.

DESCHAMPS, M.V. Vulnerabilidade socioambiental na Região Metropolitana de Curitiba. 2004. Tese (Doutorado em Meio Ambiente e Desenvolvimento) Universidade Federal do Paraná, Curitiba, 2004.

GUIMARÃES, M. Conceitos e práticas em Educação Ambiental na escola. Brasília:MEC/MMA/UNESCO, 2007.

JANKE,N; TOZONI-REIS, M.F.C. Produção coletiva de conhecimentos sobre a qualidade de vida : por uma Educação Ambiental participativa e emancipatória. Ciência \& Educação, São Paulo,v.14,n.1,p.147-157, 2008.

LOUREIRO, C.F.B. Premissas teóricas para uma educação ambiental transformadora. Ambiente e Educação, Rio Grande, 8:34-54, 2003.

LIMA, M.J.G.S. e VASCONCELLOS, M. das M.N. A Educação ambiental como disciplinar escolar: explicitando a tensão entre teoria e prática. Anais do IV Encontro de Pesquisa em Educação ambiental. Rio Claro, UNESP, 2007 (CD).

MONTEZUNA, R. C. M.; OLIVEIRA, R. R. Natureza e sociedade no Município de Duque de Caxias: os significados dos espaços vazios. Rio de Janeiro: PUCRIO/NIMA/Imprensa Oficial do estado do RJ/Petrobrás. 2009.15p. Disponível em <www.nima.puc-rio.br>. Acesso em: 15 jan 2014.

RODRIGUES, M.I.; MOLINA, A.A. Conselho Escolar: Uma proposta de gestão para envolver a participação comunitária de maneira mais atuante, consciente e crítica na escola. O professor PDE e os desafios da escola pública paranaense. Paraná:

Secretaria de Educação, 2012.

SOUZA, A.Q.; CERATI, T.M. Educação Ambiental e participação social na resolução de conflitos: estudo de caso em uma unidade de conservação urbana de São Paulo, Brasil. IX Encontro Nacional de Pesquisa em Educação em Ciências(IXENPEC). Água de Lindóia - São Paulo. 2013 Disponível em: <http://www.adaltech.com.br/sigeventos/abrapec2013/admin/pro_frm_filtro.asp?BCK= P2\&strFormato=HTML1\&eveId=1>. Acesso em : 16 mar.2014.

TORRES, H. Desigualdades ambiental em São Paulo. Tese de doutorado em Ciências Sociais. Campinas. IFCH-Unicamp, 1997. 
TOZONI-REIS. Educação Ambiental na Escola Básica: Reflexões sobre a prática dos professores. Revista Contemporânea de Educação, vol.7, nº 14, ago/dez, 2012.

WESTRUPP, M.F. Gestão escolar participativa: novos cenários de competência participativa (Dissertação de Mestrado). Universidade do Estado de Santa Catarina. Programa de Pós-Graduação em Educação, 2003. 